phosphorylated after forskolin treatment. EP3C has only one Ser and does not conform to the PKA consensus sequence. Thus the work by Namba et al. ${ }^{3}$ may provide insights into the mechanisms of negative, as well as positive, regulation of $\mathrm{G}$-protein-coupled receptors.

Henrik G. Dohlman

Department of Pharmacology, Yale University School of Medicine, POBOX 9812,

New Haven,

Connecticut 06536, USA

\section{Water in life}

SIR - Segel and Tyson in Correspondence ${ }^{1}$ tried to defend Maddox's assertion ${ }^{2}$ that molecular biology lacks a quantitative dimension. Maddox then went on to discuss ${ }^{3}$ an example of an attempt to redress the balance in describing a quantification of the hydration of glucose ${ }^{4}$.

In describing the interaction of glucose and water, the assumption in classical biochemistry has been that metabolically active glucose is free within the pathways of the cell and that water is just "ordinary' free water ${ }^{5-7}$. When a calculable theory is available, quantitative considerations fall easily into place, that of classical biochemistry being the law of mass action.

Maddox's suggestion in the first of his two articles mentioned above ${ }^{2}$ was to resurrect the law of mass action, but the past 20 years have shown that this may apply only following cataclysmic cell disruption to yield aqueous solutions in vitro ${ }^{8}$, and is generally inappropriate to the interior of the cell in vivo. It is because no adequate or simple alternative has been found that molecular biology languishes in its role as a descriptive discipline.

Maddox's second article on this topic ${ }^{3}$ finished with the words "real water". The problem of describing the physical state of water is extremely complex ${ }^{7}$, and as yet no calculable theory exists with which to begin to consider water's interactions with other molecules. Albert Szent-Györgyi himself said" that "life is water dancing to the tune of the solids".

\section{Denys N. Wheatley}

Department of Pathology.

University of Aberdeen,

Aberdeen AB9 2ZD, UK

1. Segel, L. \& Tyson, J. J. Nature 357,106 (1992).

2. Maddox. J. Nature 355, 201 (1992).

3. Maddox, J. Nature 364, 669 (1993)

4. Cramer, C. J. \& Truhlar, D. G. J. Am. chem. Soc. 115 Cramer, C. J. \& Truhl

5. Negendank, W. \& Edelmann, L. (eds) The State of intracellular Water 2, No. 2, 1-114 (1988).

6. Clegg, J. S. Collective Phenomena 3, 289-312 (1981).

7. Ling, G. N. A Revolution in the Physiology of the Living Cell (Krieger, Malabar, Florida, 1992).

8. McConkey, E. Proc. natn. Acad. Sci. U.S.A. 79, 32363240 (1982)

9. Szent-Györgyi, A. Perspect. Biol. Med. 14, 239-249 (1971).

\section{Death and c-fos}

SIR - Smeyne et al. ${ }^{1}$ suggest that continuous expression of c-fos precedes programmed cell death (apoptosis) in vivo. They do not show, however, that fos-lac Z is expressed in the specific cells that go on to die in vivo and the developmental examples they choose do not exclude other explanations for c-fos expression.

First, their tooth example (Fig. $1 d$ of ref. 1) discusses and illustrates the socalled enamel knot. But the structure expressing the lac $Z$ marker they show is not the enamel knot but the dental papilla mesenchyme. The enamel knot is a transitory structure present at the late cap stage of development within the enamel organ ${ }^{2}$. The fos-lac $Z$ labelled cells of the dental papilla mesenchyme do not normally undergo programmed cell death, but differentiate into the cells hat will form dentine (odontoblasts) and the adult dental pulp.

Their second example is the midline epithelium of the secondary palate ${ }^{1}$. Medial edge epithelial cells of the palate, however, do not die, but rather migrate ${ }^{3}$ : indeed, the reference quoted by Smeyne et al. ${ }^{1}$ makes this very point ${ }^{4}$ ! Further, the c-fos expression patterns in the palate are not consistent with c-fos expression preceding programmed cell death. For many years, it has been known that the biochemical changes which precede medial edge epithelial cell differentiation (death?) occur about 24 hours before the event (see ref. 5 for review). However, Smeyne et al. ${ }^{\prime}$ illustrate c-fos expression only where the medial edge epithelia touch and fuse to form a midline epithelial seam (their Fig. 1e). Where the medial edge epithelia are not in contact (Fig. 1f) there is no c-fos expression. However, these events are separated by only a few hours. If c-fos is a harbinger of death, one would expect to see the expression about 24 hours previously.

Interestingly, these patterns of fos-lac Z expression in the developing tooth and palate $^{1}$ resemble those of various cytokines, particularly transforming growth factor $-\beta$ family members ${ }^{6,7}$. In the palate, transient expression of transforming growth factor $\beta 3$ in the medial edge epithelia ${ }^{6}$ matches closely that reported by Smeyne et al. for fos-lacZ. Prolonged c-fos expression in development may therefore correlate better with cytokine signalling at sites of cellular interactions

\section{Scientific Correspondence}

Scientific Correspondence is intended to provide a forum in which readers may raise points of a scientific character. They need not arise out of anything published in Nature. In any case, priority will be given to letters of fewer than 500 words and five references. than with imminent programmed cell death.

\section{MarkW. J. Ferguson}

School of Biological Sciences,

University of Manchester,

ManchesterM13 9PT, UK

Morgan And CurRan RePly - Ferguson suggests that we do not show that cells expressing fos-lacZ go on to die in vivo. But Fig. 2 of our paper shows fos-lac $Z$ staining in the cytoplasm and remnants of hippocampal neurons following treatment with the neurotoxin kainic acid. We cited several examples of the association between fos-lac Z expression and cell death in vivo, but not that the fos-lacZ-positive cells went on to die in all cases. We had to remove an additional figure demonstrating further examples of the association because of Nature's space constraints. We did not wish to imply that fos-lacZ expression occurs exclusively in dying cells; indeed, we have previously documented c-fos expression in proliferating and differentiating cell populations.

Ferguson further suggests that the developmental examples we chose are problematic. Unfortunately, for reasons of space we had to delete data on fos-lacZ expression in the periderm, interdigital web cells and hypertrophic chondrocytes; all circumstances in which developmentally programmed cell death is documented. Expression of fos-lac $Z$ in the medial edge epithelium of the palate is indeed a complex phenomenon, and our discussion of this point was also curtailed for the sake of brevity. It is certainly of great interest to determine the fate of fos-lacZ-positive cells in this structure.

Regarding fos-lac $Z$ expression in the developing tooth, we have published a correction $^{1}$ about our misidentification of the enamel knot. We thank A. Lumsden and I. Thesleff for bringing this to our attention, and apologise again for any confusion this may have caused.

The association of fos-lac $Z$ expression with TGF $\beta$ family members was also omitted from our paper for space reasons, and is mentioned in ref. 8. Ferguson may wish to consider the possibility we are now investigating, that cytokines such as TGF $\beta$ may actually contribute to cell death.

\section{J. M. Morgan}

J. Curran

Roche Institute of Molecular Biology,

Nutley,

New Jersey 07110, USA

1. Smeyne, R. J. et al. Nature 363, 166-169 (1993): correction 365, 279 (1993)

. Mackenzie, A., Ferguson, M. W. J. \& Sharpe, P. T. Deveiopment 115, 403-420 (1992)

3. Carette, M. J. M. \& Ferguson, M. W. J. Development 114 379-388(1992)

4. Shuler, C. F. et al. Devi Biol. 154, 318-330 (1992).

5. Ferguson, M. W. J. Development 103, Suppl. 41-60 (1988).

6. Fitzpatrick, J et al Development 109, 585-595 (1990)

7. Varahtokari, A. etal. Development 113, 985-994 (1991)

8. Molinar-Rode, R. et al. Molec. cell. Biol. 13, 3213-3220 (1993). 